\title{
A POSSIBLE WAY FOR EVOLUTION OF THE INTELLECT OF INTELLIGENT BEINGS
}

\author{
Leonid V. Ksanfomality \\ Space Research Institute, Academy of Science of USSR \\ 84/32 Profsoyuznaya Str., 117810 Moscow, USSR
}

\begin{abstract}
$\underline{\text { Summary }}$
The development of technology shows some interesting trends and laws that have been repeated in many areas of knowledge. These trends are a temporal character of the functioning of the most effective developing technologies. A specific feature of these trends is that the decay of some old technology and its replacement by new technology just coincides (as a law) with the period of most perfect state of the old one. Together with this replacement, the progress in technology sometimes leads to the creation of new scientific and technological branches and even to some unexpected social phenomena.

There are grounds to suppose that as a result of the development of science and technological innovations, it is possible that in the not too distant future on the earth, the individuals will appear, that together with many features of the human's way of thinking, will have a special property, that we call the superintellect. This is not a service robot, the appearance of which is already determined by the development of technology. The superintellect could arise at the convergence of branches of knowledge, including electronics, optoelectronics, software and the physics of the brain. Some of these frontiers remain absolutely untouched; others seem achievable even now. The appearance on Earth of superintellect will introduce a lot of social, ethical and other problems but will also raise the intellectual power of our civilization to a tremendous extent.
\end{abstract}

